\title{
Validity and reliability of body composition analysers in children and adults
}

\author{
Nicole E. Jensky-Squires, Christina M. Dieli-Conwright, Amerigo Rossuello, David N. Erceg, \\ Scott McCauley and E. Todd Schroeder* \\ Division of Biokinesiology and Physical Therapy, School of Dentistry, Clinical Exercise Research Center, University of Southern \\ California, 1540 East Alcazar Street, CHP-155, Los Angeles, CA 90033, USA
}

(Received 28 September 2007 - Revised 13 December 2007 - Accepted 7 January 2008 - First published online 18 March 2008)

We tested the validity and reliability of the BioSpace InBody 320, Omron and Bod-eComm body composition devices in men and women ( $n$ 254; 21-80 years) and boys and girls ( $n 117 ; 10-17$ years). We analysed percentage body fat (\%BF) and compared the results with dual-energy X-ray absorptiometry (DEXA) in adults and compared the results of the InBody with underwater weighing (UW) in children. All body composition devices were correlated $(r 0.54-0.97 ; P \leq 0 \cdot 010)$ to DEXA except the Bod-eComm in women aged $71-80$ years $(r 0.54 ; P=0 \cdot 106)$. In girls, the InBody \%BF was correlated with UW $(r \quad 0.79 ; P \leq 0.010)$; however, a more moderate correlation $(r 0.69 ; P \leq 0.010)$ existed in boys. Bland-Altman plots indicated that all body composition devices underestimated $\% \mathrm{BF}$ in adults $(1 \cdot 0-4.8 \%)$ and overestimated $\% \mathrm{BF}$ in children $(0.3-2.3 \%)$. Lastly, independent $t$ tests revealed that the mean \%BF assessed by the Bod-eComm in women (aged 51-60 and 71-80 years) and in the Omron (age 18-35 years) were significantly different compared with DEXA $(P \leq 0 \cdot 010)$. In men, the Omron (aged 18-35 years), and the InBody (aged 36-50 years) were significantly different compared with DEXA $(P=0.025 ; P=0.040$ respectively). In addition, independent $t$ tests indicated that the InBody mean \% BF in girls aged 10-17 years was significantly different from UW ( $P=0 \cdot 001)$. Pearson's correlation analyses demonstrated that the Bod-eComm (men and women) and Omron (women) had significant mean differences compared with the reference criterion; therefore, the \% $\mathrm{BF}$ output from these two devices should be interpreted with caution. The repeatability of each body composition device was supported by small CV $(<3.0 \%)$.

Body fat: Bioelectrical impedance: Dual-energy X-ray absorptiometry: Underwater weighing

Childhood and adult obesity is an epidemic in the $\operatorname{USA}^{(1-3)}$ and it is important to have valid and reliable tools to assess growth and body composition. It is essential that we develop safe and accurate tools to assess body composition as well as devices that are affordable. Devices that accurately depict body fat percentage (\%BF) can be used as a tool to evaluate an individual's weight loss or gain over a period of time. Body composition analysis is important for understanding proportional changes in fat and lean mass for healthy individuals as well as individuals with various health conditions. Over the past several years there has been an increase in the marketing and sales of economical body composition analysers (i.e. bioelectrical impedance devices). Therefore, a greater need has developed to evaluate the accuracy of these body composition devices. In addition, practical indicators of $\% \mathrm{BF}$ for different age ranges and sex are needed for epidemiological and clinical studies.

Traditionally, assessing body composition relied upon the principle of underwater weighing, regarded as the 'gold standard ${ }^{\text {(4); }}$ however, technology has improved and various devices have been introduced to evaluate body composition. Dual-energy X-ray absorptiometry (DEXA) has become the preferred method for measuring body composition ${ }^{(5)}$. DEXA is considered to be highly accurate and precise ${ }^{(6)}$; it is often used as a criterion method ${ }^{(6)}$ for the assessment of body composition, justified by successful validation against multi-component models ${ }^{(7)}$. Unfortunately, the use of DEXA is limited in many environments due to inaccessibility, exposure to low-dose radiation and the high cost of the scanner. Alternatively, it is also possible to calculate $\% \mathrm{BF}$ using bioelectrical impedance analysis (BIA). BIA has been widely used in athletics and health clinics because of its relative low cost and ease of use. Lastly, another safe and practical method to assess body composition is near-IR interactance (NIA) that uses wavelengths of harmless low-intensity near-IR light to calculate $\% \mathrm{BF}$.

The purpose of the present study was to evaluate the validity and reliability of different body composition devices. We compared \%BF of the BioSpace InBody 320 (BIA), Omron (BIA) and Bod-eComm (NIA) with DEXA for a large heterogeneous population of men and women, and compared the results of the BioSpace InBody 320 with underwater weighing in children. We hypothesised that the \%BF measured on each device would strongly correlate with DEXA for adults and with underwater weighing for children. The aim of the present study was to evaluate whether the two BIA and NIA body composition analysers tested were valid and reliable for a large cohort of individuals. 


\section{Experimental methods}

Validity of the body composition analysers was determined by comparing \% BF measures from the InBody, Omron and Bod-eComm with the \%BF assessed by DEXA for adults. Reliability of each device was determined after each measurement was repeated consecutively three times. The values were averaged for analysis; however, the subjects only completed one DEXA scan, as this was the reference criterion. Similarly, the InBody \%BF was compared with the underwater weighing measurements in children. The children repeated the InBody three times and the underwater weighing was repeated until the child had at least three similar tests that did not differ by more than $100 \mathrm{~g}$. All tests were performed in the same order to eliminate changes in body-water distribution (InBody, Omron, Bod-eComm, DEXA for adults and InBody and then underwater weighing for children). Each body composition device requires different body positions, from lying supine, standing or seated; thus to eliminate potential error we standardised the order. We did not experience any aberrations in the devices, as the three repeated measurements for any given device did not differ by more than $0.3 \%$.

\section{Participants}

All participants were recruited from local newspaper advertisement or by word of mouth. Participants were required to provide written informed consent before study participation. All children were required to have his or her parent/guardian sign informed consent. The study was reviewed and approved by the University of Southern California Institutional Review Board. A total of 254 adults and 117 children participated in the study. The age groups (in years) were separated into the following categories for analysis with the number of women and men, or girls and boys, listed respectively in parentheses: 10-17 years (sixty-five girls and fifty-two boys); 18-35 years (forty-four women and forty men); 36-50 years (thirty-four women and thirty-six men); 51-60 years (twenty-five women and nineteen men); 61-70 years (nineteen women and ten men); 71-80 years (ten women and seventeen men). Food intake and hydration status were not monitored as part of the study.

\section{Equipment}

Omron bioelectrical impedance analysis. The Omron Body Fat Analyzer model HBF-360 (Omron Healthcare, Inc., Vernon Hills, IL, USA) is a portable, handheld device that sends a non-detectable low electrical current of $50 \mathrm{kHz}$ and $500 \mu \mathrm{A}$ through the body to determine the amount of fat tissue. Muscle, blood vessels and bone are body tissues with large water content, thus they conduct the electrical current with less resistance. Body fat has a lower electrical conductivity. \% BF is calculated using five variables: electric resistance, height, weight, age and sex. The Omron was not used to assess \% BF in children as the system does not contain the appropriate age range as a choice. The tester measured each individual's height and weight and input the different variables into the device. Participants stood with correct posture (straight torso) while holding the device in both hands with straightened arms. The participant held the grip electrodes by placing the palm of his or her hand on the top and the bottom of the electrodes while placing his or her thumbs up, resting on the top of the unit. The tester pressed the start button to begin \% BF analysis. Consistent measuring conditions were maintained for each test.

InBody 320 bioelectrical impedance analysis. The InBody 320 Body Composition Analyzer (BioSpace, Seoul, Korea) is a segmental impedance device measuring the voltage drop in the upper and lower body. The participant stood on the device while it measured body weight, and age, height and sex were entered on the touch screen. The InBody uses eight points of tactile electrodes (contact at the hands and feet). This detects the amount of segmental body water. The technique uses multiple frequencies to measure intracellular and extracellular water separately. The frequency of $50 \mathrm{kHz}$ measures extracellular water while frequencies above $200 \mathrm{kHz}$ measure intracellular water. Segmental analysis can calculate slight differences by sex, age and race without using empirical estimation.

Bod-eComm near-infrared interactance. The Bod-eComm XL (Futrex, Hagerstown, MD, USA) uses wavelengths of harmless low-intensity near-IR light. Body fat absorbs these wavelengths of light while lean mass reflects them. Light absorption and reflection were measured to determine $\% \mathrm{BF}$. The Bod-eComm was not used to assess \% BF in children, as the system does not contain the appropriate age range. The tester typed the following variables into the Bod-eComm program installed on a computer: age, sex, weight, height and exercise status. The tester placed the Bod-eComm light wand firmly against the skin over the biceps muscle belly of the participant's dominant arm while following the computer-prompted instructions. Each \%BF analysis was completed after calibrating the device.

\section{Dual-energy X-ray absorptiomtry}

All adult participants underwent a total body DEXA (model DPX-IQ 2288 with Smart Scan version 4.7e; Lunar Radiation Corporation, Madison, WI, USA) to assess fat mass. The Lunar model uses a constant potential X-ray source and a K-edge filter to achieve a congruent beam of stable dualenergy radiation. To assess body composition, the DEXA scanner performed a series of transverse $1 \mathrm{~cm}$ scans starting at the subject's head progressing toward the feet. A BioImaging phantom acrylic block (VCP-057; Bio-Imaging Technologies, Inc., Newtown, PA, USA) was used to determine the accuracy of the Lunar model to measure body fat ${ }^{(8)}$. The phantom consists of four stacked acrylic blocks which are used in conjunction with sheets of vinyl and polyvinyl chloride (PVC). The acrylic blocks act to simulate fat mass while the PVC and vinyl sheets act to simulate lean tissue. By adjusting the number of PVC and vinyl sheets that are laid over the acrylic block, three differing levels of tissue density can be simulated to give a high, medium and low percentage fat reading. The percentage fat readings for the phantom and the DPX-IQ (Lunar Radiation Corporation) for three predetermined levels of tissue density, respectively, were: high fat, 44.2 and $42.4 \%$; medium fat, 23.4 and $20.0 \%$; low fat, 8.6 and $6.1 \%$. For all three tissue density settings, the DPX-IQ (Lunar Radiation Corporation) tended to underestimate percentage fat by $1.8,3.4$ and $2.5 \%$, respectively. Quality 
assurance was performed using a single acrylic block three times per week to confirm the accuracy and precision of the DEXA system. The same experienced investigator was responsible for performing and analysing all scans.

\section{Underwater weighing}

The children were voluntarily submerged in water while sitting in a specially designed chair that was suspended from a scale above the tank. They were asked to expel all the air in their lungs by exhaling through their mouth and nose while lowering themselves under water in a tank designed to assess hydrodensitometry. We used predicted residual volume equations for children $(10-17 \text { years old })^{(9,10)}$. Once submerged, a Chatillion 1300 series autopsy scale (New York, NY, USA) was used to determine the underwater weight. The scale weight was recorded and the three heaviest of five to ten trials was used to calculate body density. The body density value was then entered into the Siri equation (Lohman sex- and age-adjusted) $^{(11)}$ to determine \%BF. Since the underwater weighing method has been the gold standard for measurement of body composition, we used this as our criterion method ${ }^{(12,13)}$ for children.

\section{Statistical analysis}

Statistical analyses were performed using SPSS for windows (version 14.0; SPSS, Inc., Chicago, IL, USA). Pearson's correlation coefficients were used to determine the association between each body composition device and DEXA or underwater weighing. This analysis was used to study correlations between variables. Values of $r 0.7$ or greater were taken as indicating a strong correlation with a level of significance of $0 \cdot 01$. Bland-Altman plots ${ }^{(14)}$ were developed using MedCalc for Windows (version 9.2.0.0; MedCalc Software, Mariakerke, Belgium) to compare the DEXA (reference criterion) with one of the other body composition analysers (Omron, InBody, Bod-eComm) for adults and underwater weighing (reference criterion) compared with the InBody for children. In this graphical method the differences between the reference criterion and one of the other body composition analysers were plotted against the averages of the two devices ${ }^{(14)}$. BlandAltman plots were further supported by performing Student's independent $t$ tests (two-sided), which examined mean differences in $\% \mathrm{BF}$ between devices. Trend lines were added to the Bland-Altman plots to demonstrate the relationships.
Pearson's correlation analyses were performed between the variables generated on the $x$ and $y$ axes of the BlandAltman plots.

$\mathrm{CV}$ were calculated using the following formula: $\mathrm{CV}=100 \times($ within-person standard deviation/within-person mean). Additionally, a $1 \times 3$ (DEXA $\times$ Omron, InBody, Bod-eComm) repeated-measures ANOVA was conducted in adults to determine if $\% \mathrm{BF}$ differed between devices after the data were categorised by sex and age. Because multiple tests were performed, results were interpreted using Bonferroni's adjustment factor. Significance was accepted at $P \leq 0 \cdot 05$.

\section{Results}

Table 1 summarises the demographics of the study participants. Mean $\% \mathrm{BF}$ is reported in Table 2, which includes the average $\% \mathrm{BF}$ for the three trials for each body composition device.

All body composition devices were significantly correlated to DEXA for all age groups $(P<0.050)$ except the BodeComm in women $71-80$ years of age $(P=0 \cdot 106)$ (Table 3$)$. Underwater weighing in children was significantly correlated to the InBody $(P \leq 0 \cdot 010)$, with a stronger correlation found among girls ( $r$ 0.79) than boys ( $r$ 0.69) (Table 3). In addition, we observed consistent reliability across all body composition analysers. The consistency across the three repeated tests is supported by the small $(<3.0 \%) \mathrm{CV}$ for all body composition devices (range from 0.6 to $3.0 \%$ ) (Table 4 ).

Bland-Altman plots are useful to reveal relationships between the differences and the averages of various devices, to assess systematic bias, and to identify outliers ${ }^{(14,15)}$. Men and women, and boys and girls were graphed separately; however, age categories were not used for the Bland-Altman plots (Figs. 1-3). Mean values above zero represent an overestimation of $\% \mathrm{BF}$, whereas values below zero represent an underestimation of \%BF. Figs. 1 and 2 (a), (b) and (c) demonstrate that the InBody, Omron and Bod-eComm tend to underestimate $\% \mathrm{BF}$ in both men and women, as the means ranged from -1.0 to -4.8 (Table 2). Fig. 3 demonstrates that the InBody slightly overestimates \% BF in boys (a) and in girls (b). Additionally, we used the Bland-Altman variables and performed Pearson's correlations to determine that the Bod-eComm had significant yet weak correlations in both men and women $(P \leq 0.02 ; r-0.2)$. Similarly, in women, the Omron had a significant but weak correlation $(P=0 \cdot 00$; $r-0 \cdot 3)$. These two devices had significant mean differences

Table 1. Baseline characteristics of the participant population

(Mean values and standard deviations)

\begin{tabular}{|c|c|c|c|c|c|c|c|c|}
\hline \multirow[b]{3}{*}{ Age group (years) } & \multicolumn{4}{|c|}{ Males } & \multicolumn{4}{|c|}{ Females } \\
\hline & \multicolumn{2}{|c|}{ Height $(\mathrm{cm})$} & \multicolumn{2}{|c|}{ Weight (kg) } & \multicolumn{2}{|c|}{ Height (cm) } & \multicolumn{2}{|c|}{ Weight (kg) } \\
\hline & Mean & SD & Mean & SD & Mean & SD & Mean & SD \\
\hline $10-17$ & 171.0 & 9.6 & 63.6 & 12.9 & 159.0 & 9.0 & $57 \cdot 0$ & $13 \cdot 2$ \\
\hline $18-35$ & $176 \cdot 6$ & $7 \cdot 0$ & 76.8 & $9 \cdot 2$ & 163.7 & $6 \cdot 0$ & $58 \cdot 3$ & $8 \cdot 7$ \\
\hline $36-50$ & $180 \cdot 8$ & $6 \cdot 7$ & 83.4 & $10 \cdot 6$ & $165 \cdot 0$ & $6 \cdot 4$ & 65.9 & $12 \cdot 6$ \\
\hline $51-60$ & 179.2 & $7 \cdot 4$ & 88.6 & 16.9 & 164.5 & 8.0 & $65 \cdot 7$ & $12 \cdot 8$ \\
\hline $61-70$ & $176 \cdot 5$ & 11.0 & $90 \cdot 3$ & $16 \cdot 6$ & $163 \cdot 2$ & 5.6 & 74.3 & $14 \cdot 3$ \\
\hline $71-80$ & 174.4 & $5 \cdot 8$ & 75.4 & 11.9 & $170 \cdot 0$ & $6 \cdot 7$ & $79 \cdot 8$ & $12 \cdot 9$ \\
\hline
\end{tabular}


Table 2. Percentage body fat (\%BF) by age group and sex for each body composition device† (Mean values and standard deviations)

\begin{tabular}{|c|c|c|c|c|c|c|c|c|c|c|}
\hline \multirow{2}{*}{$\begin{array}{l}\text { \%BF by } \\
\text { Age group (years) }\end{array}$} & \multicolumn{2}{|c|}{ DEXA } & \multicolumn{2}{|c|}{$\begin{array}{l}\text { Underwater } \\
\text { weighing }\end{array}$} & \multicolumn{2}{|c|}{$\begin{array}{l}\text { InBody } 320 \\
\text { (BIA) }\end{array}$} & \multicolumn{2}{|c|}{ Omron (BIA) } & \multicolumn{2}{|c|}{$\begin{array}{l}\text { Bod-eComm } \\
\text { (NIA) }\end{array}$} \\
\hline & Mean & SD & Mean & SD & Mean & SD & Mean & SD & Mean & SD \\
\hline \multicolumn{11}{|l|}{ Males } \\
\hline $10-17$ & \multicolumn{2}{|c|}{ - } & $12 \cdot 0$ & \multirow[t]{6}{*}{$5 \cdot 6$} & $12 \cdot 3$ & $5 \cdot 0$ & \multicolumn{2}{|c|}{ - } & \multicolumn{2}{|c|}{ - } \\
\hline $18-35$ & $16 \cdot 4$ & $5 \cdot 2$ & - & & $15 \cdot 9$ & $5 \cdot 8$ & $13 \cdot 8^{\star}$ & 4.9 & $16 \cdot 6$ & 5.5 \\
\hline $36-50$ & $20 \cdot 7$ & $6 \cdot 2$ & - & & $19 \cdot 4^{*}$ & $14 \cdot 0$ & 18.9 & 5.5 & $17 \cdot 8$ & $6 \cdot 7$ \\
\hline $51-60$ & $26 \cdot 0$ & 4.4 & - & & $24 \cdot 0$ & $6 \cdot 3$ & $25 \cdot 6$ & $6 \cdot 1$ & $24 \cdot 1$ & $7 \cdot 7$ \\
\hline $61-70$ & 29.4 & $13 \cdot 2$ & - & & $26 \cdot 8$ & 11.9 & $30 \cdot 2$ & 8.4 & $26 \cdot 0$ & 11.0 \\
\hline $71-80$ & 24.5 & 8.9 & - & & $22 \cdot 7$ & 8.5 & 28.8 & 7.5 & 21.4 & $6 \cdot 7$ \\
\hline \multicolumn{11}{|l|}{ Females } \\
\hline $10-17$ & \multicolumn{2}{|c|}{-} & $23 \cdot 0$ & \multirow[t]{6}{*}{$8 \cdot 3$} & $25 \cdot 4^{*}$ & 8.4 & \multicolumn{2}{|c|}{-} & \multicolumn{2}{|c|}{-} \\
\hline $18-35$ & $26 \cdot 5$ & $5 \cdot 6$ & - & & 24.1 & 5.6 & $22 \cdot 1^{*}$ & $5 \cdot 0$ & 24.9 & 4.9 \\
\hline $36-50$ & $31 \cdot 8$ & 9.8 & - & & $28 \cdot 0$ & 9.9 & 30.1 & $11 \cdot 0$ & $26 \cdot 5$ & $7 \cdot 3$ \\
\hline $51-60$ & 33.4 & 7.5 & - & & $28 \cdot 2$ & 8.3 & $30 \cdot 6$ & 5.5 & $27 \cdot 7^{\star}$ & 6.1 \\
\hline $61-70$ & $40 \cdot 0$ & $9 \cdot 7$ & - & & $36 \cdot 5$ & $10 \cdot 0$ & 39.5 & $6 \cdot 3$ & $32 \cdot 4$ & $8 \cdot 1$ \\
\hline $71-80$ & $42 \cdot 1$ & $6 \cdot 7$ & - & & $37 \cdot 1$ & 5.6 & $40 \cdot 7$ & 3.6 & $32 \cdot 5^{*}$ & 4.3 \\
\hline
\end{tabular}

DEXA, dual-energy X-ray absorptiometry; BIA, bioelectrical impedance analysis; NIA, near-IR interactance.

${ }^{*}$ Mean value was significantly different from that using the reference criterion (DEXA in adults and underwater weighing in children) $(P \leq 0.05)$.

† Includes values that were not different from the reference criterion unless noted. For details of subjects and procedures, see Table 1 and Experimental methods.

when comparing the device with the reference criterion for each individual, suggesting they may not be valid body composition devices for use in these populations (Fig. 1 (c), Fig. 2 (b) and (c)). All other variables in the Bland-Altman plots were not significantly correlated $(P \geq 0 \cdot 2)$ in men and women, boys and girls.

The overall ANOVA for comparison was not significant; however, the data indicate that the Bod-eComm has the largest underestimation of \% BF which is supported by an independent $t$ test (Table 2) and correlation analyses. Furthermore, independent $t$ tests reveal that the \% $\mathrm{BF}$ assessed by the

Table 3. Correlations of body composition analysers compared with dual-energy X-ray absorptiometry (DEXA) or underwater weighing $\dagger$ (Pearson correlation coefficients and number of subjects)

\begin{tabular}{|c|c|c|c|c|c|c|}
\hline \multirow[b]{2}{*}{ Age group (years) } & \multicolumn{2}{|c|}{$\begin{array}{c}\text { InBody } 320 \\
\text { (BIA) }\end{array}$} & \multicolumn{2}{|c|}{$\begin{array}{l}\text { Omron } \\
\text { (BIA) }\end{array}$} & \multicolumn{2}{|c|}{$\begin{array}{l}\text { Bod-eComm } \\
\text { (NIA) }\end{array}$} \\
\hline & $r$ & $n$ & $r$ & $n$ & $r$ & $n$ \\
\hline \multicolumn{7}{|l|}{ Males } \\
\hline $10-17$ & $0.69^{\star} \ddagger$ & 52 & - & & - & \\
\hline $18-35$ & $0.91^{\star}$ & 40 & $0.78^{*}$ & 40 & $0.76^{\star}$ & 40 \\
\hline $36-50$ & $0.92^{*}$ & 36 & $0.83^{*}$ & 36 & $0.83^{\star}$ & 36 \\
\hline $51-60$ & $0.75^{\star}$ & 19 & $0.67^{*}$ & 19 & $0 \cdot 70^{\star}$ & 19 \\
\hline $61-70$ & $0.97^{*}$ & 10 & $0.95^{\star}$ & 10 & $0.83^{*}$ & 10 \\
\hline $71-80$ & $0.92^{*}$ & 17 & $0.92^{*}$ & 14 & $0 \cdot 81^{*}$ & 17 \\
\hline \multicolumn{7}{|l|}{ Females } \\
\hline $10-17$ & $0.79^{*} \ddagger$ & 65 & - & & - & \\
\hline $18-35$ & $0.80^{\star}$ & 44 & $0.74^{*}$ & 44 & $0.54^{*}$ & 44 \\
\hline $36-50$ & $0.96^{\star}$ & 34 & $0.92^{*}$ & 34 & $0.90^{\star}$ & 34 \\
\hline $51-60$ & $0.92^{*}$ & 25 & $0.92^{*}$ & 25 & $0.78^{\star}$ & 25 \\
\hline $61-70$ & $0.96^{\star}$ & 19 & $0.89^{\star}$ & 16 & $0.92^{*}$ & 10 \\
\hline $71-80$ & $0 \cdot 83^{*}$ & 10 & $0.95^{\star}$ & 8 & 0.54 & 10 \\
\hline
\end{tabular}

BIA, bioelectrical impedance analysis; NIA, near-IR interactance.

* Significantly correlated to the gold standard $(P \leq 0.01)$.

$\dagger$ For details of subjects and procedures, see Table 1 and Experimental methods.

$\ddagger$ Values were compared with underwater weighing while other devices were compared with DEXA.
Bod-eComm in women 51-60 and 71-80 years of age and the Omron in women 18-35 years of age are significantly different compared with DEXA $(P \leq 0 \cdot 010)$ (Table 2). Similarly, independent $t$ tests demonstrated \%BF measured using the InBody significantly differed from DEXA in males 36-50 years of age $(P=0 \cdot 040)$ as well as the Omron in males $18-35$ years of age $(P=0 \cdot 025)$. Lastly, independent $t$ tests also indicate that $\% \mathrm{BF}$ analysed by the InBody in girls $10-17$ years of age is significantly different from underwater weighing $(P=0.001)$ (Table 2).

\section{Discussion}

Body composition data are frequently collected in clinics, sports medicine, nutrition and other health-related fields. Although DEXA and underwater weighing can provide accurate results, these methods are often inaccessible to the general population and potentially expensive. The devices chosen for estimating \%BF should be both valid and reliable. We have examined the validity and reliability of different body composition analysers in children and adults. We sought to establish whether differences in the devices were sensitive to age and sex. The data suggest that $\% \mathrm{BF}$ for the InBody, Omron and

Table 4. Reliability of body composition analysers*

\begin{tabular}{lcc}
\hline Body composition analyser & CV\%† & Subjects tested $(n)$ \\
\hline InBody 320 (BIA) (adults) & $1 \cdot 8$ & 254 \\
Omron (BIA) & $0 \cdot 6$ & 217 \\
Bod-eComm (NIA) & $2 \cdot 4$ & 252 \\
InBody 320 (BIA) (children) & $3 \cdot 0$ & 117 \\
\hline
\end{tabular}

BIA, bioelectrical impedance analysis; NIA, near-IR interactance.

${ }^{*}$ Each person repeated the body composition analysis three times and the average percentage body fat was used to compute CV (CV\%). For details of subjects and procedures, see Table 1 and Experimental methods.

$\dagger C V=100 \times$ (within-person standard deviation/within-person mean). 

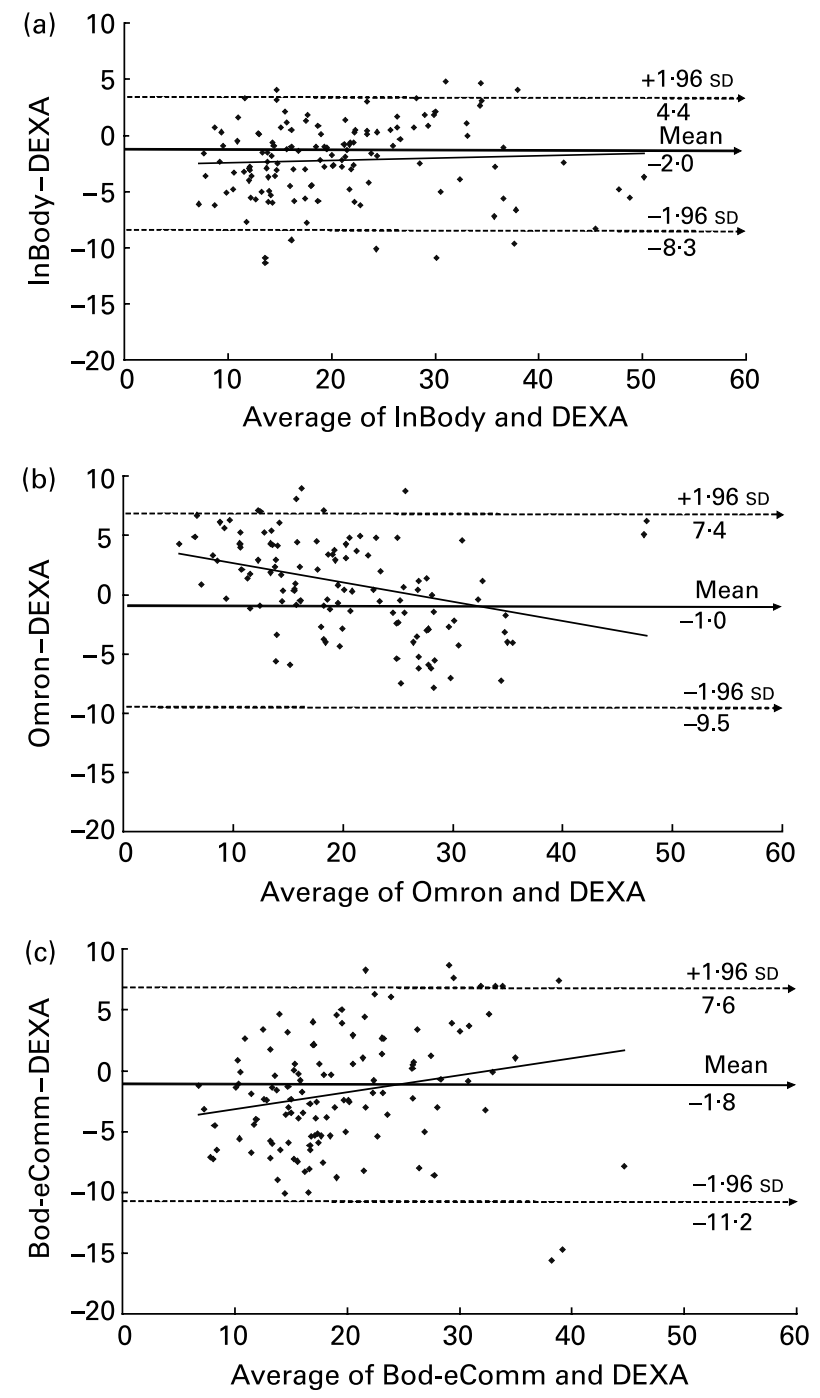

Fig. 1. Bland-Altman plots with limits of agreement (LOA) for men relating percentage body fat (\%BF) of the (a) InBody 320 (bioelectrical impedance analysis; $\mathrm{BIA} ; r$ 0.05), (b) Omron (BIA; $r-0.03$ ) and (c) Bod-eComm (nearIR interactance; $r 0.20$ ) to dual-energy X-ray absorptiometry (DEXA). The difference between the tested device and DEXA (tested device - DEXA) is plotted against the \%BF mean for each male subject. The solid line represents how much the device underestimates (negative number) or overestimates (positive number) the tested device and the dotted lines represent the LOA from the mean.

Bod-eComm are linearly associated with the values obtained from DEXA for men and women and in all age groups except 71-80-year-old women using the Bod-eComm; however, the limited number of older women subjects $\left(\begin{array}{ll}n & 10\end{array}\right)$ may have artificially influenced the results. Additionally, the InBody values were correlated with underwater weighing in children.

Previous validation studies in adults and children have reported that BIA devices tend to underestimate or overestimate $\% \mathrm{BF}$ in relation to $\mathrm{DEXA}^{(16)}$. BIA tends to overestimate $\% \mathrm{BF}$ when subjects are relatively lean and underestimate $\%$ BF when subjects are obese ${ }^{(16,17)}$. We validated two BIA devices (Omron and InBody). In general, we determined few differences in \%BF between the DEXA and Omron except
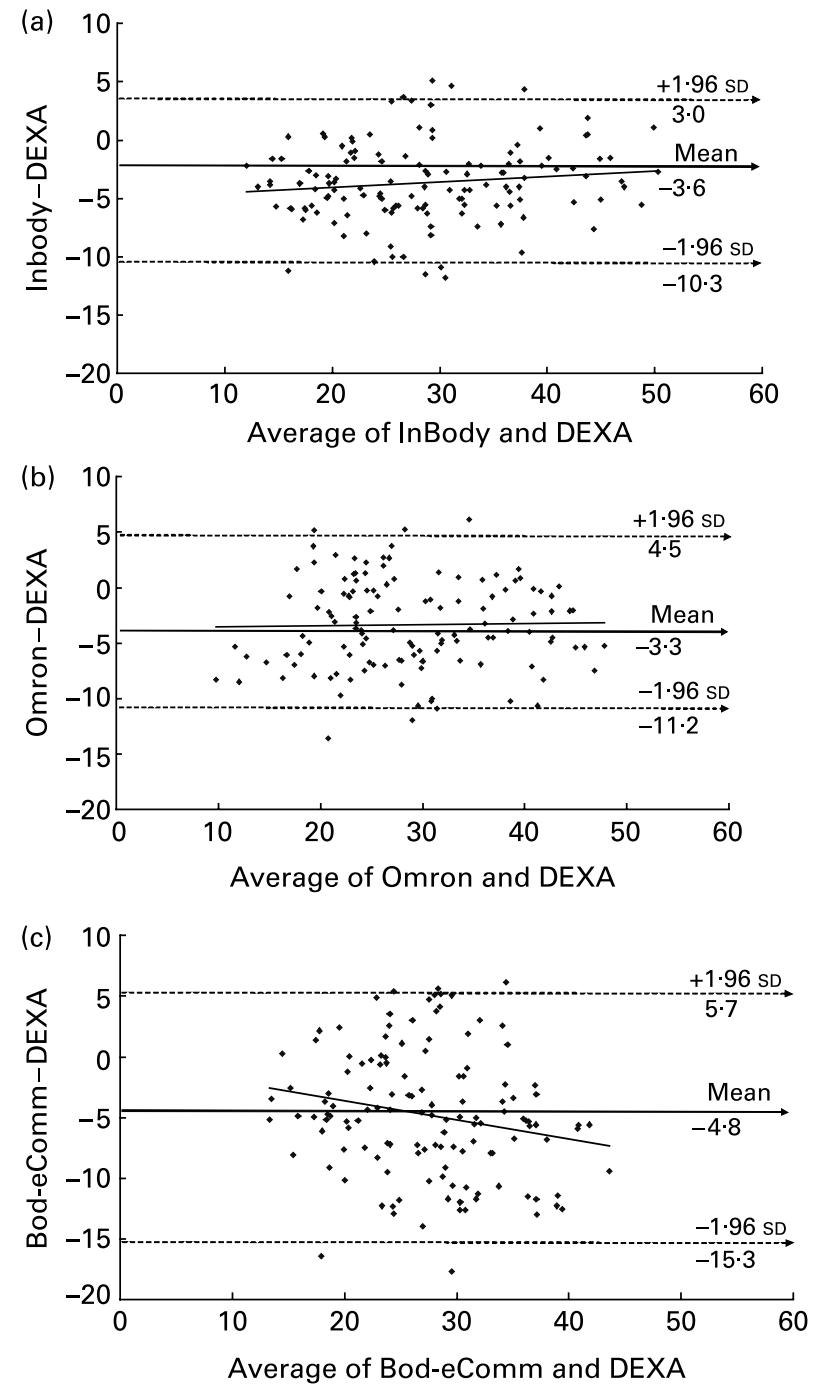

Fig. 2. Bland-Altman plots with limits of agreement (LOA) for women relating percentage body fat (\%BF) of the (a) InBody 320 (bioelectrical impedance analysis; BIA; $r$ 0.13), (b) Omron (BIA; $r$ 0.02) and (c) Bod-eComm (near-IR interactance; $r-0 \cdot 20$ ) to dual-energy X-ray absorptiometry (DEXA). The difference between the tested device and DEXA (tested device DEXA) is plotted against the \%BF mean for each female subject. The solid line represents how much the device underestimates (negative number) or overestimates (positive number) the tested device and the dotted lines represent the LOA from the mean.

in young men and women $18-35$ years of age. Similar to our findings, previous studies determined that the \%BF measured by the Omron tends to underestimate $\% \mathrm{BF}^{(18)}$. It is possible that arm length may influence the body fat calculations by bioelectrical impedance ${ }^{(19,20)}$. Moreover, segmental BIA, such as the InBody, has great potential to accurately assess total and appendicular body composition estimates ${ }^{(21)}$. In adults, we determined that \% BF between the DEXA and InBody only differed in males 36-50 years of age. Additionally, in young girls, there was a significant difference in $\% \mathrm{BF}$ compared with underwater weighing. Discrepancies may exist due to differences in sample size, ethnicity, fitness level and hydration status. In general, BIA devices are safe, quick and easy to use with little or no training. 

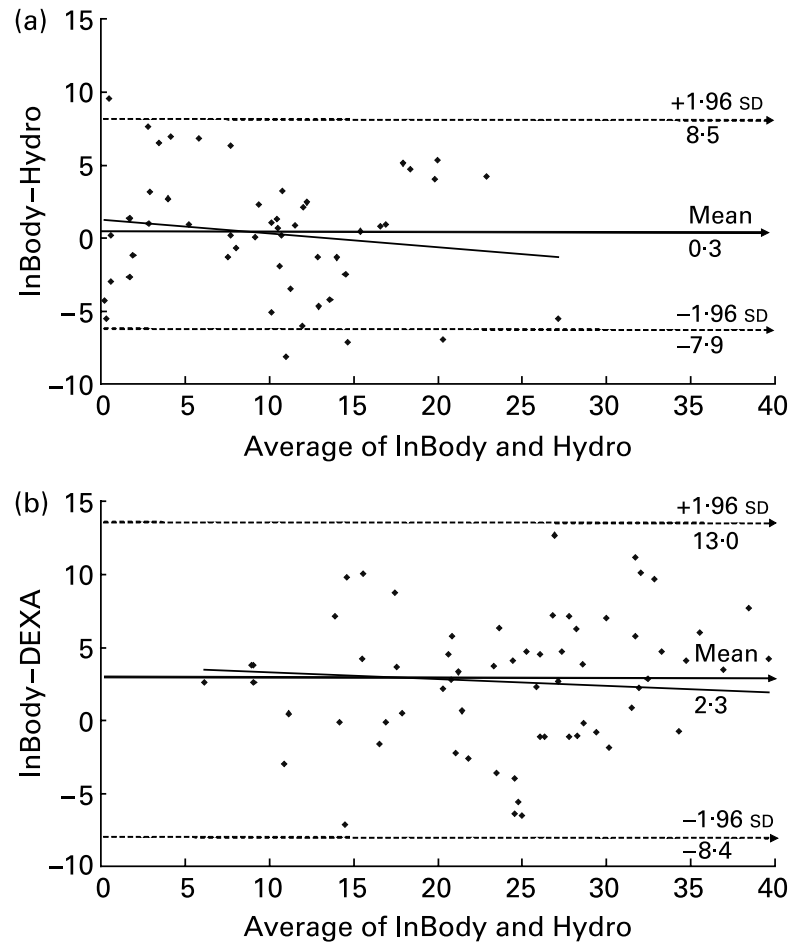

Fig. 3. Bland-Altman plots with limits of agreement (LOA) relating percentage body fat (\%BF) in children using the InBody 320 (bioelectrical impedance analysis) for both (a) boys $(r-0.14)$ and (b) girls $(r-0.16)$ to underwater weighing (Hydro). The difference between the InBody and underwater weighing (InBody - Hydro) is plotted against the \%BF mean for each boy or girl subject. The solid line represents how much the device underestimates (negative number) or overestimates (positive number) the tested device and the dotted lines represent the LOA from the mean.

Numerous studies advocate using NIA for assessment of body composition in various populations ${ }^{(22-24)}$. Prior studies comparing NIA (Futrex 5000 Body Composition Analyzer; Futrex, Hagerstown, MD, USA) with underwater weighing determined that NIA overestimated body fat in lean subjects with less than $8 \%$ fat and underestimated in subjects with greater than $30 \%$ body fat ${ }^{(25)}$. Similar to the previous reports testing body composition analysers, we determined that the Bod-eComm underestimated \%BF. Panotopoulos et al. ${ }^{(26)}$ indicated that in obese women BIA, NIA and DEXA cannot be used interchangeably. Although other studies have demonstrated that these devices are highly correlated to DEXA, Bland-Altman plots indicate that the large limits of agreement suggest BIA and NIA do not effectively reproduce accurate results in obese women ${ }^{(26)}$. Likewise, in healthy women, we determined that the Bod-eComm significantly differed from DEXA (51-60 and 71-80 years of age).

The agreement between DEXA or underwater weighing compared with the other body composition devices was assessed using Bland-Altman analysis ${ }^{(14,15)}$. The BlandAltman plots were categorised by sex since there were differences in body composition between men and women and boys and girls. The body composition devices utilised in the present study were correlated to the reference criterion; however, they underestimated $\% \mathrm{BF}$ for all conditions except for the InBody which overestimated \% BF in boys and girls. The data indicate that these devices may not be appropriate for all body types, and measured differences in \%BF may be due to variation in ethnicity, hydration status and activity level.

There are several limitations of the present study. Although DEXA is widely accepted as the 'gold standard' for body composition analysis in adults and underwater weighing as the 'gold standard' for children, these techniques are not universally accepted. Potentially, the criterion methods used in the present study may not be the most precise or accurate for the populations tested. Direct analysis of body composition can only be performed by chemical analysis of cadavers ${ }^{(17)}$ and other methods serve as only indirect measurements of $\%$ BF. Concerns have been reported about the ability of DEXA to accurately assess soft tissue ${ }^{(27,28)}$. Additionally, DEXA and underwater weighing are often validated in a specific population that does not account for all ages, ethnicities and body types.

There are potential limitations with underwater weighing as well. Hydration can influence an accurate underwater weighing assessment ${ }^{(12)}$ as well as a participant's comfort in water and ability to expire air from his or her lungs while remaining steady under water as the scale is read. It is difficult for children to perform the tasks necessary to achieve an accurate underwater weighing. Other studies have confirmed that some children cannot complete the requirements and must be eliminated from the study ${ }^{(29)}$. Additionally, we used an estimated residual volume equation to predict residual volume $^{(30)}$.

An experienced technician is essential to optimally perform the procedures associated with underwater weighing. It is also important to understand that the equipment and skills of the individual performing the testing can influence reliability. Our data are representative of a healthy population; therefore, our data cannot be applied to compromised populations. The different populations, lifestyles, activity levels, body types, hydration status, developmental stages, ethnicities and use of different body composition devices may explain some of the discrepancies between our findings and those of other studies. Subsequent validation studies would be beneficial to elucidate the differences between devices after adjusting for possible confounding variables ${ }^{(10)}$.

The strengths of the present study are supported by the large sample size, strong correlations and small mean differences comparing the chosen devices with reference criterions. After performing independent $t$ tests for all age groups in men and women, the data suggest that the Omron appears to be an accurate device in all populations except young adults (18-35 years of age), the InBody accurately assesses \%BF in all populations except 36-50-year-old men, while the Bod-eComm tends to inaccurately measure $\% \mathrm{BF}$ in middle age and older women (51-60, 71-80 years of age). The goal of the present study was to determine if these instruments accurately measure individual \%BF; thus it is important to report that a large error does exist when applying each device to an individual. In general, our data demonstrate that the InBody 320, Omron and Bod-eComm are correlated and not significantly different from the reference criterions; however, large individual error exists. After all age groups for men and women were combined and correlation analyses were performed, the Bod-eComm (men and women) and Omron (women) had significant mean differences compared with the reference criterion, therefore the $\% \mathrm{BF}$ output from 
these two devices should be interpreted with caution. Future validation studies are warranted to explain the few significant differences found between the devices and to determine whether these devices are valid alternatives to DEXA or underwater weighing.

\section{Acknowledgements}

There were no conflicts of interest and all sources of funding were from either the Division of Biokinesiology and Physical Therapy at the University of Southern California or Stayhealthy Inc. (Monrovia, CA, USA). All authors contributed by helping with study design, testing subjects and data analysis.

\section{References}

1. Boehmer TK, Brownson RC, Haire-Joshu D \& Dreisinger ML (2007) Patterns of childhood obesity prevention legislation in the United States. Prev Chronic Dis 4, A56.

2. Levy RL, Finch EA, Crowell MD, Talley NJ \& Jeffery RW (2007) Behavioral intervention for the treatment of obesity: strategies and effectiveness data. Am J Gastroenterol 102, $2314-2321$.

3. Wang Y \& Beydoun MA (2007) The obesity epidemic in the United States - gender, age, socioeconomic, racial/ethnic, and geographic characteristics: a systematic review and metaregression analysis. Epidemiol Rev 29, 6-28.

4. Katch FI \& Michael ED (1969) Densitometric validation of six skinfold formulas to predict body density and percent body fat of 17-year-old boys. Res $Q \mathbf{4 0}, 712-716$.

5. Aasen G, Fagertun H \& Halse J (2006) Body composition analysis by dual X-ray absorptiometry: in vivo and in vitro comparison of three different fan-beam instruments. Scand J Clin Lab Invest 66, 659-666.

6. Lohman T (2005) Dual Energy X-ray Absorptiometry. Champaign, IL: Human Kinetics Ltd.

7. Sopher AB, Thornton JC, Wang J, Pierson RN Jr, Heymsfield SB \& Horlick M (2004) Measurement of percentage of body fat in 411 children and adolescents: a comparison of dualenergy X-ray absorptiometry with a four-compartment model. Pediatrics 113, 1285-1290.

8. Diessel E, Fuerst T, Njeh CF, Tylavsky F, Cauley J, Dockrell M \& Genant HK (2000) Evaluation of a new body composition phantom for quality control and cross-calibration of DXA devices. J Appl Physiol 89, 599-605.

9. Cook CD \& Hamann JF (1961) Relation of lung volumes to height in healthy persons between the ages of 5 and 38 years. $J$ Pediatr 59, 710-714.

10. Stocks J \& Quanjer PH (1995) Reference values for residual volume, functional residual capacity and total lung capacity. ATS Workshop on Lung Volume Measurements. Official Statement of The European Respiratory Society. Eur Respir J 8, 492-506.

11. Lohman TG (1989) Assessment of body composition in children. Pediatr Exerc Sci 1, 19-30.

12. Thompson DL, Thompson WR, Prestridge TJ, Bailey JG, Bean MH, Brown SP \& McDaniel JB (1991) Effects of hydration and dehydration on body composition analysis: a comparative study of bioelectric impedance analysis and hydrodensitometry. J Sports Med Phys Fitness 31, 565-570.
13. Harsha DW \& Bray GA (1996) Body composition and childhood obesity. Endocrinol Metab Clin North Am 25, 871-885.

14. Bland JM \& Altman DG (1986) Statistical methods for assessing agreement between two methods of clinical measurement. Lancet i, 307-310.

15. Altman DG \& Bland JM (1995) Absence of evidence is not evidence of absence. BMJ 311, 485 .

16. Sun G, French CR, Martin GR, et al. (2005) Comparison of multifrequency bioelectrical impedance analysis with dualenergy X-ray absorptiometry for assessment of percentage body fat in a large, healthy population. Am J Clin Nutr 81, 74-78.

17. Hosking J, Metcalf BS, Jeffery AN, Voss LD \& Wilkin TJ (2006) Validation of foot-to-foot bioelectrical impedance analysis with dual-energy $\mathrm{X}$-ray absorptiometry in the assessment of body composition in young children: the EarlyBird cohort. Br J Nutr 96, 1163-1168.

18. Lintsi M, Kaarma H \& Kull I (2004) Comparison of hand-tohand bioimpedance and anthropometry equations versus dual-energy X-ray absorptiometry for the assessment of body fat percentage in 17-18-year-old conscripts. Clin Physiol Funct Imaging 24, 85-90.

19. Snijder MB, Kuyf BE \& Deurenberg P (1999) Effect of body build on the validity of predicted body fat from body mass index and bioelectrical impedance. Ann Nutr Metab 43, $277-285$.

20. Deurenberg P, Andreoli A, Borg P, Kukkonen-Harjula K, de Lorenzo A, van Marken Lichtenbelt WD, Testolin G, Vigano R \& Vollaard N (2001) The validity of predicted body fat percentage from body mass index and from impedance in samples of five European populations. Eur J Clin Nutr 55, 973-979.

21. Malavolti M, Mussi C, Poli M, Fantuzzi AL, Salvioli G, Battistini N \& Bedogni G (2003) Cross-calibration of eight-polar bioelectrical impedance analysis versus dual-energy X-ray absorptiometry for the assessment of total and appendicular body composition in healthy subjects aged 21-82 years. Ann Hum Biol 30, 380-391.

22. Lukaski HC (1987) Methods for the assessment of human body composition: traditional and new. Am J Clin Nutr 46, 537-556.

23. Elia M, Parkinson SA \& Diaz E (1990) Evaluation of near infrared interactance as a method for predicting body composition. Eur J Clin Nutr 44, 113-121.

24. Brooke-Wavell K, Jones PR, Norgan NG \& Hardman AE (1995) Evaluation of near infra-red interactance for assessment of subcutaneous and total body fat. Eur J Clin Nutr 49, 57-65.

25. McLean KP \& Skinner JS (1992) Validity of Futrex-5000 for body composition determination. Med Sci Sports Exerc 24, 253-258.

26. Panotopoulos G, Ruiz JC, Guy-Grand B \& Basdevant A (2001) Dual X-ray absorptiometry, bioelectrical impedance, and near infrared interactance in obese women. Med Sci Sports Exerc 33, 665-670.

27. Roubenoff R, Kehayias JJ, Dawson-Hughes B \& Heymsfield SB (1993) Use of dual-energy X-ray absorptiometry in body-composition studies: not yet a "gold standard". Am J Clin Nutr 58, 589-591.

28. Kohrt WM (1995) Body composition by DXA: tried and true? Med Sci Sports Exerc 27, 1349-1353.

29. Claros G, Hull HR \& Fields DA (2005) Comparison of air displacement plethysmography to hydrostatic weighing for estimating total body density in children. BMC Pediatr 5, 37.

30. Goldman HI \& Becklake MR (1959) Respiratory function tests; normal values at median altitudes and the prediction of normal results. Am Rev Tuberc 79, 457-467. 